\title{
Uncovering Engagement Networks for Adaptation in Three Regional Communities: Empirical Examples from New South Wales, Australia
}

\author{
Rebecca Cunningham ${ }^{1, *(D)}$, Brent Jacobs ${ }^{1}\left(\mathbb{D}\right.$ and Thomas G. Measham ${ }^{2}(\mathbb{D}$ \\ 1 Institute of Sustainable Futures, University of Technology, Ultimo, Sydney, NSW 2007, Australia; \\ Brent.Jacobs@uts.edu.au \\ 2 Commonwealth Science and Industrial Research Organisation, QCAT, Pullenvale, QLD 4069, Australia; \\ Tom.Measham@csiro.au \\ * Correspondence: Rebecca.Cunningham@uts.edu.au; Tel.: +61(0)475-415-245
}

Citation: Cunningham, R.; Jacobs, B.; Measham, T.G. Uncovering Engagement Networks for Adaptation in Three Regional Communities: Empirical Examples from New South Wales, Australia. Climate 2021, 9, 21. https://doi.org/ $10.3390 /$ cli9020021

Received: 23 November 2020

Accepted: 18 January 2021

Published: 21 January 2021

Publisher's Note: MDPI stays neutral with regard to jurisdictional claims in published maps and institutional affiliations.

Copyright: (c) 2021 by the authors. Licensee MDPI, Basel, Switzerland. This article is an open access article distributed under the terms and conditions of the Creative Commons Attribution (CC BY) license (https:// creativecommons.org/licenses/by/ $4.0 /)$.

\begin{abstract}
Climate change is a significant challenge for policy makers, planners and communities. While adaptation responses are generally recognised to be place-based, policy processes on adaptation often reside with central (state or national) governments that may be remote from regional communities. In this paper, we contribute to the literature regarding how diverse regional communities engage with planning and policy for climate adaptation, which is important for successful implementation. We adopt a social network analysis (SNA) approach that enables an exploration of the interaction of community networks with policy information. There are limited empirical studies of information sharing about climate adaptation policy through community knowledge networks. One previous study, located in coastal New South Wales, Australia, mapped the community's knowledge acquisition and diffusion to reveal the underlying network structures that influenced policy engagement pathways. However, further studies are needed to determine how the features of community networks may change with local context (e.g., coastal versus inland). This paper extends previous studies to compare and contrast adaptation knowledge networks in three NSW communities: Shoalhaven (the original coastal study site), Bega (coastal) and Orange (inland). Findings suggest that the presence of a natural resource-dependent industry, local geographies and boundary spanners acting as network knowledge brokers are factors influencing community knowledge flows. The work further demonstrates the utility of SNA to measure knowledge networks that can inform government engagement and communication with communities on climate adaptation policy.
\end{abstract}

Keywords: adaptation policy; climate change policies; community participation; knowledge networks; environmental governance; social network analysis

\section{Introduction}

Climate change is a significant challenge for policy makers and planners that manifests through a range of impacts on government services, businesses and communities [1,2]. The governance of climate change is complex, operating formally and informally at multiple levels across society (international, national, province/state and local) with a tendency to separate and isolate mitigation and adaptation responses at national and sub-national levels, respectively [3]. Climate change adaptation, that is, action to reduce the harm caused by the impacts of climate change, is needed to cope with existing changes in the climate system that are locked in from previous emissions of greenhouse gasses [4]. Community adaptation is not static; rather, it is a continuous, dynamic and scalable process with adaptation responses generally recognised to be place-based. Adaptation decisions are made on a daily basis by individuals, households, organisations and businesses (e.g., travel modes, recycling and consumption options) [5]. Furthermore, adaptations may be either intentional or autonomous [6] and are uniquely influenced by local context $[7,8]$. 
These factors require close engagement with communities in developing formal policy responses. However, formal adaptation policy decisions often remain entrenched within the central government and may be remote from the regional issues they seek to address [9]. This situation may be problematical for policy makers, as their reach into local networks is limited [10], rendering grassroots action by communities, which might help inform policy development, largely opaque.

A key challenge for engaging local communities in climate adaptation is that policy makers have limited understanding of the ways that communities share and convey climate knowledge among themselves [11]. Empirical evidence is limited about the success of outcomes from climate adaptation [12]; however, previous research suggests that climate adaptation networks are important to adaptation outcomes, albeit difficult to identify [13]. This may be due to the influence of shadow systems or informal networks often at play within adapting communities [14]. Although it can be difficult to ascertain how adaptation information is being shared within communities, there are approaches, such as social network analysis (SNA), that may allow these knowledge flows to be uncovered [11,13], which in turn may inform interventions to further enhance knowledge flows $[15,16]$. The community structures engaged in adaptation may be understood more deeply by uncovering the underlying social networks that are activated around particular issues, one of the most important being climate change.

This paper reports research to understand the interaction between the formal and informal adaptation knowledge networks in three regional communities in NSW. Here, we define formal networks as connections to government and formal structures relating to climate change adaptation policy (e.g., IPCC and research organizations); informal networks are connections with non-government organisations, community-based organisations and media (e.g., television, newspapers and social media). We build on earlier research conducted on this topic that demonstrated the utility of social network analysis for identifying the underlying structures that influence community engagement pathways when communicating about climate change [11]. In doing so, the paper addresses the need for more empirical examples of social networks within the adaptation space [13,17].

\section{Materials and Methods}

We used social network analysis (SNA) to reveal knowledge network structures and identify the elements of these networks influencing community knowledge flows about climate adaptation. The research was co-designed with policy makers, climate adaptation staff from the New South Wales Office of Environment and Heritage (NSW OEH), who were interested in understanding how to engage more effectively with local communities at risk from climate impacts. We adopted a co-design approach because it is potentially transformative and incorporates an in-depth, reflexive learning process in situ between policy makers and researchers [18]. This was a novel approach that could inform future work, and the methodology could be replicated. This is demonstrated in this synthesis paper as the findings follow on from the first study in Shoalhaven (see previous outputs from first case study [11]). This section provides contextual details relating to the case study sites and wider region, followed by a brief introduction and description of the social network analysis (SNA) approach employed in the research.

\subsection{Case Study Sites and Context}

In accordance with the co-design approach to research, three regions were jointly selected by the research team with government research partners: Shoalhaven, Bega Valley and Orange. These regions, each within the State of NSW were selected due to their ability to provide an appropriate level of comparison and contrasting characteristics that may inform future policy development in the state. These three regions are geographically diverse and vary in their exposure to climate change impacts [19], with the first two being coastal and the final case study an inland location (Figure 1). Table 1 provides an overview of the characteristics of these regions. 


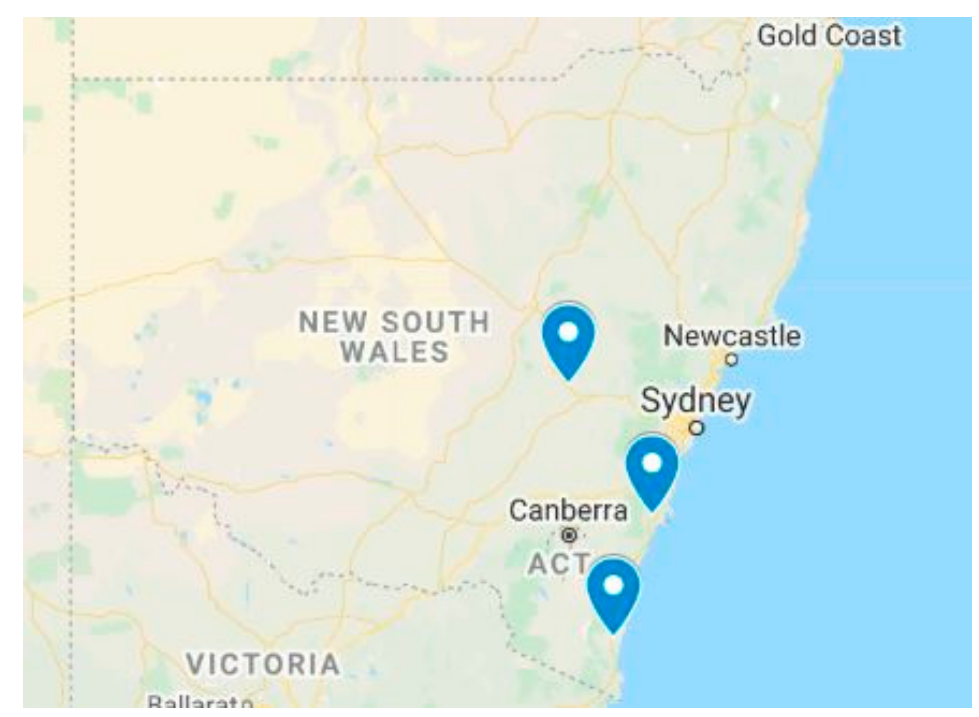

Figure 1. Geographical locations of three case studies in New South Wales, Australia.

Table 1. Overview of each region.

\begin{tabular}{|c|c|c|c|}
\hline & Shoalhaven & Bega Valley & Orange \\
\hline First people & $\begin{array}{c}\text { Wodi Wodi and Wandandian } \\
\text { Aboriginal people }\end{array}$ & Yuin-Monaro Aboriginal people & Wiradjuri Aboriginal people \\
\hline Population & $\sim 98,000$ & $\sim 35,000$ & $\sim 40,000$ \\
\hline \multirow[t]{6}{*}{ Local Industries } & Dairy farming & Dairy farming & $\begin{array}{c}\text { State and federal government } \\
\text { administration }\end{array}$ \\
\hline & Beef farming & Beef farming & Mining and services to mining \\
\hline & Nurseries & Timber & Hospitality \\
\hline & Manufacturing & Fishing & Tourism \\
\hline & Tourism & Oyster harvesting & Retail \\
\hline & Oyster harvesting & Tourism & Service Sector \\
\hline $\begin{array}{l}\text { Most significant } \\
\text { climate impacts }\end{array}$ & $\begin{array}{l}\text { Coastal storms } \\
\text { Riverine flooding } \\
\text { Bushfires }\end{array}$ & $\begin{array}{l}\text { Coastal storms } \\
\text { Riverine flooding } \\
\text { Bushfires }\end{array}$ & $\begin{array}{l}\text { Loss of cold nights } \\
\text { Variable rainfall } \\
\text { Rising temperatures }\end{array}$ \\
\hline
\end{tabular}

\subsubsection{Shoalhaven Region}

Shoalhaven Local Government Area (LGA) (similar to a county in USA or a municipality in Europe) is located approximately $160 \mathrm{~km}$ south of Sydney on the south coast of New South Wales, Australia (see Figure 1) [20]. Shoalhaven is a dispersed region spread over $125 \mathrm{~km}$ of coastline with the vast majority of its population located in the north east around town centres of Nowra, Jervis Bay and Sussex Inlet [20]. The region is a growing residential and tourist area, encompassing approximately $4531 \mathrm{~km}^{2}$, including substantial areas of national park, state forest, bushland, beaches and lakes [20]. Most of the population is concentrated along the coastal fringe, in major centres and numerous small settlements. Rural land is used primarily for dairy farming, beef cattle, nurseries and a growing number of more intensive agri-food activities, some near the coast, including fishing and oyster farming. The area has a strong manufacturing base, including goods such as paper, starches, ethanol, cheese, boats, avionics and building products [20]. The main sectors of employment within the region are manufacturing, government (including defence), retail and tourism [20]. These sectors are supported by building and construction, community services and education [20]. The region also has a strong cultural history with 
links to indigenous communities, i.e., the Wodi Wodi and Wandandian Aboriginal people, who have inhabited the region since before European settlement.

\subsubsection{Bega}

The Bega Valley Shire, referred to as Bega hereafter, (also known as the Sapphire Coast) is located on the far south coast of New South Wales, Australia (see Figure 1). The region is located approximately $350 \mathrm{~km}$ south of Sydney, $430 \mathrm{~km}$ north east of Melbourne and $170 \mathrm{~km}$ south east of Canberra; the region is home to the Yuin-Monaro people, with the term Bega being a derivative of the local Aboriginal term for "big camping ground" [21,22]. European settlement in the region dates from the 1830s, with the land being used primarily for beef and dairy cattle as well as sheep farming and whaling in coastal areas [22]. By the 1860s, dairy had become the primary industry, and the coastal town of Tathra was used as the primary port; today, the region remains a primary dairy producer, with Bega Cheese, manufactured by the Bega Cooperative Society Limited, being distributed across Australia and worldwide. Almost 75\% of the shire's $6277 \mathrm{~km}^{2}$ is protected National Park or State Forest [21].

\subsubsection{Orange}

The town of Orange is located in the New South Wales Central Tablelands, approximately $270 \mathrm{~km}$ north of Canberra and $260 \mathrm{~km}$ west of Sydney (See Figure 1). Orange region covers an area of approximately $285 \mathrm{~km}^{2}$, of which $90 \%$ is rural land [23]. While wheat growing was the primary agricultural land use post European settlement, there are a number of orchards and wineries which utilise the region's cool temperate climate and rich soils [24]. Orange is a fruit growing district producing apples, pears and other stone fruits such as cherries, peaches, apricots and plums. The growth of the wine industry along with the development of Orange as a gourmet food region has ensured its status as a prominent tourism destination [25]. In addition to the agricultural industries, there is a large open cut gold and copper mine located approximately $25 \mathrm{~km}$ south of Orange called the Cadia-Ridgeway Mine [26]. The region also has a strong cultural history with links to the Wiradjuri Aboriginal people who inhabited the region prior to European settlement in the early 1820 s [24].

\subsection{Projected Climate Changes for SE NSW}

The projected climate changes for these regions include increases in maximum and minimum temperatures, rainfall distribution changes and increased fire risk. Average warming varies regionally, with Shoalhaven projected to increase on average by $0.6^{\circ} \mathrm{C}$ in the near future (2020-2039) and $1.9^{\circ} \mathrm{C}$ in the far future (2060-2079); Bega is projected to increase on average by $0.6{ }^{\circ} \mathrm{C}$ in the near future (2020-2039) and $2{ }^{\circ} \mathrm{C}$ in the far future (2060-2079); Orange is projected to increase on average by $0.7^{\circ} \mathrm{C}$ in the near future (2020-2039) and $2.1^{\circ} \mathrm{C}$ in the far future (2060-2079). For detailed climate change assessments for each of these regions, please refer to the reports [27-29].

\subsection{A Mixed Method Approach}

The study used a mixed methods approach involving both quantitative and qualitative data gathering. This particular study was not an information needs analysis; rather, it was an investigative enquiry to uncover where participants currently access and share climate adaptation-related information. The quantitative component of the research used social network analysis (SNA) to uncover the shadow networks [14] and map the formal and informal social networks in the three regions. Two social networks were mapped in each of the three regions. The two networks related to the following questions "where do participants access climate adaptation information?" (access network) and "with whom do they share their information?" (share network). For more information on the social network analysis, see the following [15,30-32]. A snowball sampling technique to recruit participants was used to ensure that the most appropriate people were identified for 
interviews [15]. Our initial scoping phase involved a desktop review of the region to identify a cross-section of the community to ensure participants represented a mix of stakeholders from government, industry, non-government organisations and the broader community. Identifying characteristics of individuals such as gender, levels of education, numbers of children and religion were not included within the snowball sampling process. A table outlining the inclusion of participants in either formal or informal networks is shown below (Table 2) (additional demographic information is available in previously published reports [27-29]).

Table 2. Association of participants with formal or informal networks.

\begin{tabular}{cccc}
\hline Case Study & $\begin{array}{c}\text { Number of Formal } \\
\text { Network Participants }\end{array}$ & $\begin{array}{c}\text { Number of Informal } \\
\text { Network Participants }\end{array}$ & $\begin{array}{c}\text { Total Number } \\
\text { of Participants }\end{array}$ \\
\hline Shoalhaven & 12 & 12 & 24 \\
\hline Bega & 9 & 22 & 31 \\
\hline Orange & 15 & 16 & 31 \\
\hline
\end{tabular}

Responses to questions on accessing and sharing were used to formulate affiliation and attribute data sheets resulting in six discrete networks. Responses used for attribute data included demographic information such as name, gender, location and association (e.g., employment and community organisation membership). All identified entities (e.g., individuals, websites and newspapers) became individual nodes and were used to create directed symmetric matrices that were then analysed using specific network measures. Specifically, we used UCINet and Keyplayer software programs to undertake the SNA (Borgatti, Everett et al. 2002, Borgatti 2006). Network cohesion values were calculated for each network including the metrics of average degree, average distance, closure, components, density, diameter and fragmentation. A brief explanation of common network terms as well as the definitions of the network cohesion measures is provided in Table 3. These measures were selected because they pertained specifically to the research questions; for example, a network with higher levels of cohesion may makes it easier to share information through that network. A series of sociograms depicting the networks was made using UCInet's Netdraw software [15]. The figure layout is constrained by Euclidean distance, hence the more central nodes appear at the centre of the image, and nodes that have similar connections are closer to each other.

Table 3. Definitions of common network terms and description of network cohesion measures.

\begin{tabular}{cc}
\hline Common Terms & Definition \\
\hline Node & $\begin{array}{c}\text { Any entity within the network. This includes all participants } \\
\text { and all nominated information sources }\end{array}$ \\
\hline Tie & $\begin{array}{c}\text { Every connection between nodes is represented by a tie } \\
\text { In-degree }\end{array}$ \\
\hline Out-degree & The number of incoming ties \\
\hline Network cohesion measure & The average number of ties attributed to each node \\
\hline Average degree & The average geodesic distance amongst reachable pairs \\
\hline Average distance & Measure of the completeness of relational triads \\
\hline Closure & The number of cliques \\
\hline Components & The number of ties divided by the maximum number possible \\
\hline Density & The length of the longest geodesic across the network \\
\hline Diameter & The proportion of pairs of nodes that are unreachable \\
\hline Fragmentation &
\end{tabular}


For the qualitative component, semi-structured interviews with purposive snowball sampling were conducted with a cross-section of the community. These included formal (federal government, state government, local government, research centres) and informal groups (non-government organisations (NGO), industry and community-based organisations (CBO). The dates of data collection and numbers of formal and informal interviewees in each location are shown in Table 4. Upon participants' written consent, interviews were audio recorded, transcribed and imported into NVivo for coding and thematic analysis. The project generated a large amount of qualitative data. This paper will focus primarily on the quantitative SNA while being supplemented by the findings from the semi-structured interviews. For more information regarding the full interviews, including the coding of all content, please refer to the published project reports [23,33,34]. In broad terms, the interviews explored: (i). perceptions of climate change and adaptation; (ii). community concerns and personal experiences; (iii). roles and responsibility for adaptation policy; (iv). adequacy and usefulness of information and community engagement processes; $(v)$. types of information that interests people the most; (vi). potential changes people have made to improve liveability and business efficiency under changing climatic conditions.

Table 4. Case study and node statistics.

\begin{tabular}{|c|c|c|c|c|c|c|}
\hline & \multicolumn{2}{|c|}{ Shoalhaven } & \multicolumn{2}{|c|}{ Bega } & \multicolumn{2}{|c|}{ Orange } \\
\hline Research Undertaken & Mar.-A & r. 2014 & Oct.-N & 2014 & Nov.-D & c. 2015 \\
\hline \multirow[t]{2}{*}{ Sample Size } & \multicolumn{2}{|c|}{$\mathrm{N}=24$} & \multicolumn{2}{|c|}{$\begin{array}{c}\mathrm{N}=31 \\
(29 \text { participated } \\
\text { in SNA) }\end{array}$} & \multicolumn{2}{|c|}{$\mathrm{N}=31$} \\
\hline & Access & Share & Access & Share & Access & Share \\
\hline Network size & 165 & 194 & 175 & 209 & 212 & 205 \\
\hline \multicolumn{7}{|l|}{ Node types } \\
\hline International & 12 & 0 & 1 & 0 & 1 & 0 \\
\hline $\begin{array}{l}\text { Federal, state and local } \\
\text { government }\end{array}$ & 45 & 47 & 44 & 47 & 48 & 84 \\
\hline Non-government organisations & 14 & 15 & 24 & 51 & 17 & 28 \\
\hline Community-based organisations & 25 & 79 & 22 & 77 & 27 & 42 \\
\hline $\begin{array}{l}\text { Mass media channels } \\
\text { (e.g., tv, newspaper) }\end{array}$ & 23 & 6 & 28 & 9 & 33 & 5 \\
\hline $\begin{array}{l}\text { Mass communication channels } \\
\text { (e.g., internet) }\end{array}$ & 12 & 7 & 19 & 1 & 22 & 3 \\
\hline Social media & 5 & 5 & 26 & 8 & 9 & 1 \\
\hline Research organisations & 6 & 3 & 8 & 1 & 30 & 18 \\
\hline Total formal nodes & 77 & 65 & 77 & 99 & 96 & 130 \\
\hline Total informal nodes & 82 & 129 & 98 & 111 & 116 & 75 \\
\hline
\end{tabular}

As the three case studies were undertaken over the course of two years, with data collected at different time periods, only general comparisons about the structure and function of the regional networks are possible. In addition, there is a range of information that was collected through the semi-structured interviews that provided context for each of the locations. Although this is not expanded upon in detail here, findings from the qualitative analysis from interviews may be found in each of the respective reports $[23,33,34]$. Within this paper, key elements are extrapolated with a focus on synthesis. These elements revolve around the narratives of place and the primary industries that operate within these sites and will be outlined within the discussion. 


\section{Results}

\subsection{Access Information Results}

\subsubsection{Shoalhaven}

In total, the 24 participants interviewed in the Shoalhaven study reported a total of 165 entities from which they obtained their climate adaptation information (inclusive of the participants themselves). Of these, 12 were international entities, 45 government entities (either local, state or federal), 14 non-government organisations, 25 community-based organisations, 23 mass media entities (e.g., TV, radio or newspaper), 12 mass communication channels (e.g., internet or mobile), five social media outlets, six research organisations and 16 other entities, such as individual community members. Figure $2 \mathrm{a}$ shows the climate information access network, and Table 4 shows the network and node statistics. Nodes are coded for affiliation by colour, for degree by size and shape for gender. When analysing the cohesion of this network, the average degree of each node was 2.558 , with an average distance or reach for each node of 4.417. This means that on average, each node had ties to 2.5 alternate nodes, and through these alters could reach up to a further 4.4 alters. There was only one component in this network which had a diameter of 9 (diameter meaning that it took only nine nodes to make a path through the main component of the network) with a degree of closure of 0.15 (for full cohesion measures see Table 5).
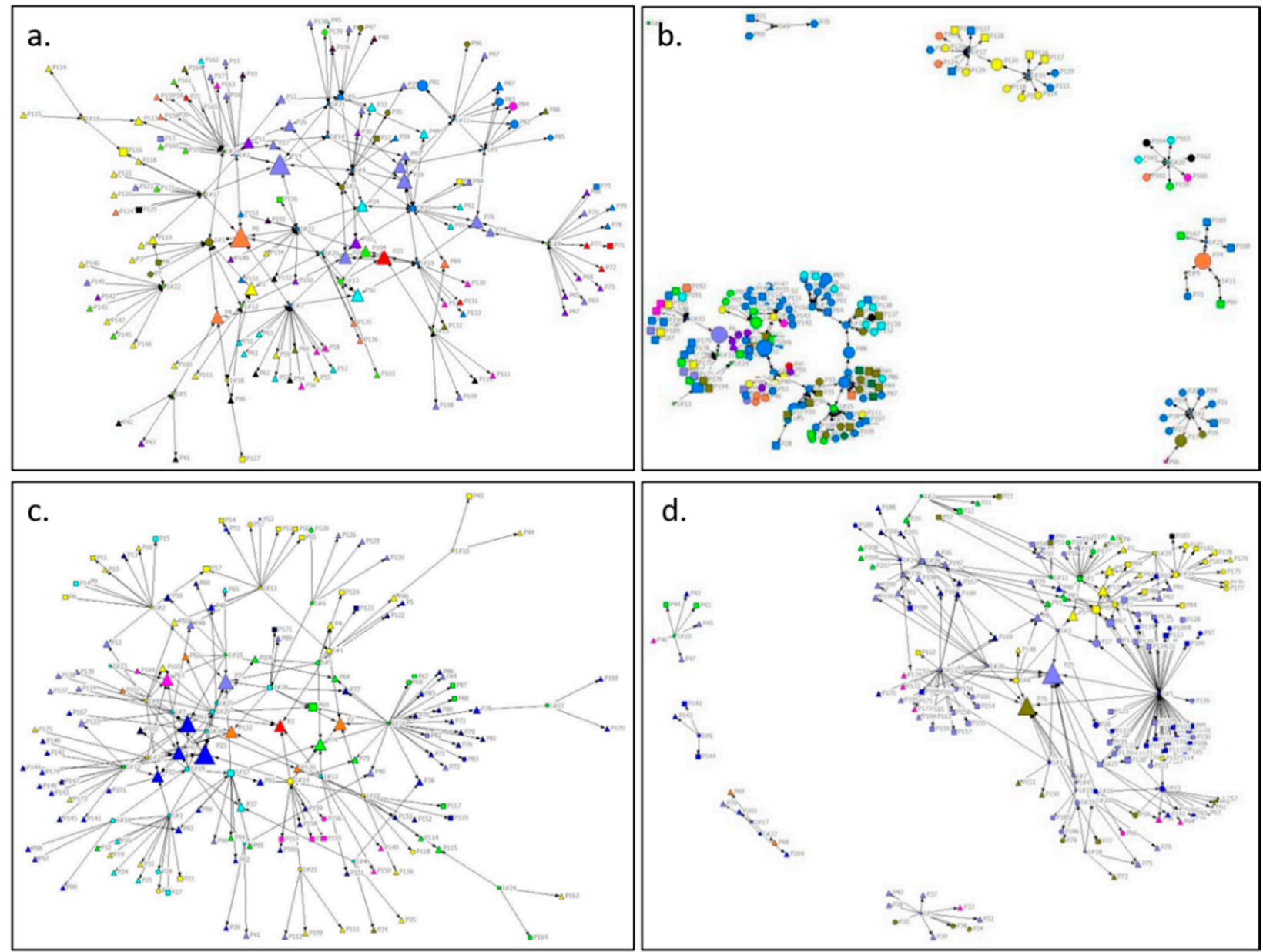

Figure 2. Cont. 

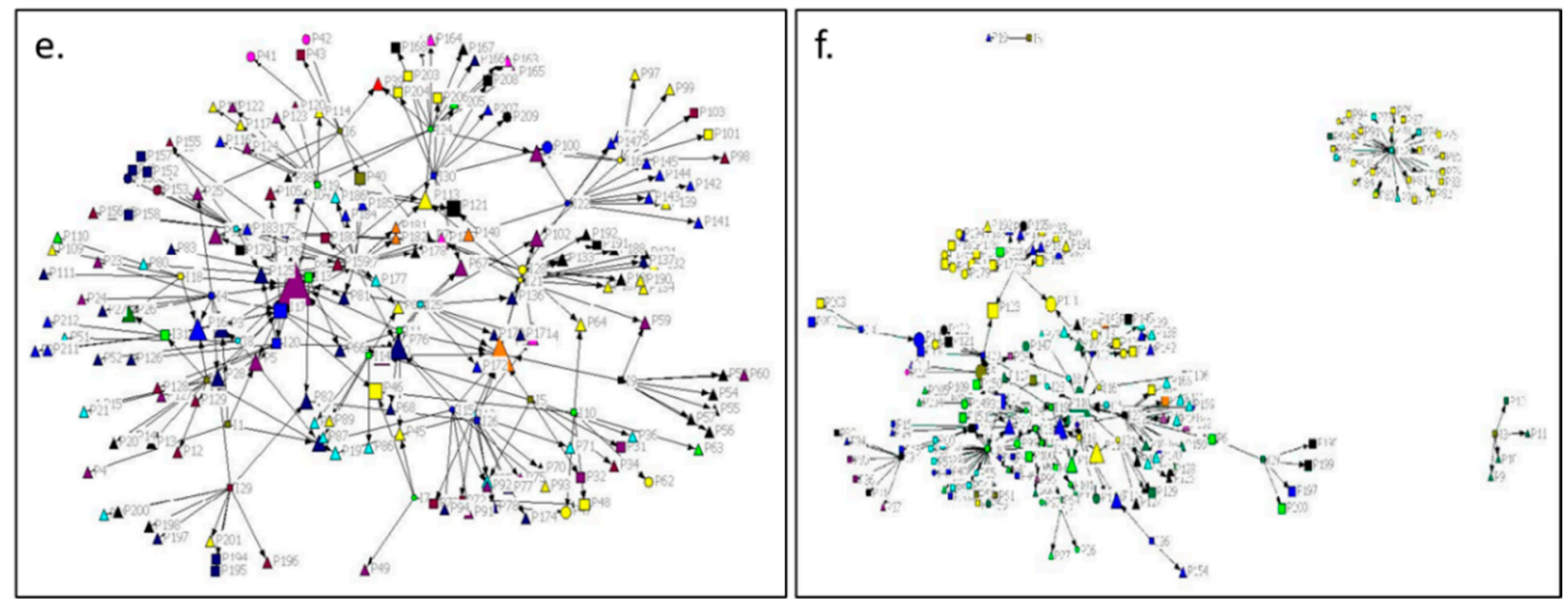

Figure 2. Access and share networks from three case studies: (a) Shoalhaven access, (b) Shoalhaven share, (c) Bega access, (d) Bega share, (e) Orange access and (f) Orange share. Symbol type denotes gender where appropriate (circle = female, square $=$ male, triangle $=$ not applicable). Symbol size denotes in-degree or the number of times that a node was mentioned by other participants. Symbol colour denotes type of organisation: international (red), local government (green), state government (yellow), federal government (orange), mass media (light purple), mass communication (dark blue), social media (pink), research centre (black), individual (khaki) and other (burgundy).

Table 5. UCInet cohesion statistics.

\begin{tabular}{ccccccc}
\hline & \multicolumn{3}{c}{ ACCESS } & \multicolumn{3}{c}{ SHARE } \\
\hline & Shoalhaven & Bega & Orange & Shoalhaven & Bega & Orange \\
\hline Average degree & 2.558 & 1.320 & 1.316 & 1.99 & 1.257 & 1.185 \\
\hline Density & 0.016 & 0.008 & 0.006 & 0.015 & 0.006 & 0.006 \\
\hline Components & 1 & 175 & 212 & 7 & 209 & 198 \\
\hline Component ratio & 0 & 1 & 1 & 0.031 & 0.995 & 0.966 \\
\hline Fragmentation & 0 & 0.989 & 0.990 & 0.449 & 0.991 & 0.978 \\
\hline Closure & 0.015 & 0.063 & 0.106 & 0.007 & 0.213 & 0.107 \\
\hline Average distance & 4.417 & 1.392 & 1.513 & 4.249 & 1.398 & 2.664 \\
\hline Diameter & 9 & 4 & 3 & 7 & 3 & 8 \\
\hline Density & 2.558 & 1.320 & 1.316 & 1.99 & 1.257 & 1.185 \\
\hline
\end{tabular}

Further analysis of the access network using Keyplayer software [35] revealed that although individuals gathered information from other sources, such as personal weather stations, websites and reports, the three nodes of the Bureau of Meteorology, ABC Radio and the Sydney Morning Herald (newspaper) could access over three quarters of the entire network with a reach of $84.2 \%$ (see Table 6).

Table 6. Keyplayer access and share.

\begin{tabular}{cccc}
\hline & SHOALHAVEN & BEGA & ORANGE \\
\hline ACCESS & Bureau of Meteorology & CSIRO & Ind CBO \\
\hline$\%$ nodes reached in the network & ABC Radio & Internet & Ind state gov \\
\hline
\end{tabular}


Table 6. Cont

\begin{tabular}{cccc}
\hline & SHOALHAVEN & BEGA & ORANGE \\
\hline SHARE & 2ST Radio & Friends & Individual state government \\
\hline & Interviewee CBO & Interviewee CBO & Individual NGO \\
\hline$\%$ nodes reached in the network & Interviewee local government & Interviewee LLS & Individual CBO \\
\hline
\end{tabular}

\subsubsection{Bega}

In total, the 29 participants interviewed in this study reported a total of 175 entities from which they obtained their climate adaptation information (inclusive of the participants themselves). Of these, one was an international entity, 44 were government entities (either local, state or federal), 24 non-government organisations (NGOs), 22 communitybased organisations (CBOs), 28 mass media entities (e.g., TV, radio or newspaper), 19 mass communication channels (e.g., internet or mobile), 26 social media outlets, eight research organisations and three other entities, such as individual community members (Figure $2 \mathrm{c}$ and Table 4).

When analysing the cohesion of this network, the average degree of each node was 1.320 , with an average distance or reach for each node of 1.392. This means that on average, each node had ties to 1.3 alternate nodes, and through these connections could reach up to a further 1.4 nodes. There were 175 components and 0.989 fragmentation in this network, which had a diameter of 4 (meaning that it took only four nodes to make a path through the large component of the network) with a degree of closure of 0.63 (Table 5). Further exploration of the data through Keyplayer demonstrated there were three key nodes in each scenario, as outlined in Table 6 . The key nodes were \#2-the CSIRO, \#7-the internet and \#23-ABC news. This analysis indicates that although individuals may gather information from other sources, such as personal weather stations, websites and reports, these three key nodes could reach three quarters of the network with a reach of $77.7 \%$.

\subsubsection{Orange}

In total, the 31 participants interviewed obtained climate change information from 212 nodes (including the participants themselves). Of these sources, one was an international entity, 48 were government entities (including federal, state and local government), 17 non-government organisations (NGOs), 27 community-based organisations (CBOs), 33 mass media (TV, radio or newspaper), 22 mass communication channels (e.g., internet or mobile), nine social media (e.g., twitter), 30 research organisations and 25 other (Figure 2e and Table 4).

For this network, the average degree of each node was 1.3, with an average distance or reach for each node of 1.5. This means that on average, each node had ties to 1.3 alternate nodes, and through these connections could reach up to a further 1.5 nodes. The network was highly fragmented with 212 components and 0.99 degrees of fragmentation; however, this network also had a diameter of 3 (that is, it took only three nodes to make a path through the network) with a degree of closure of 0.1 (for full cohesion measures, please see Table 5). The key nodes were \#I17—CBO, \#I22—state government and \#I30—state government (Table 6), and they could reach approximately $35 \%$ of the network.

\subsection{Disseminating Climate Information}

\subsubsection{Shoalhaven}

While participants accessed information from a range of sources, including the three key nodes in each access network listed above, they disseminate their knowledge in more dense clusters. In particular, interviewees primarily shared information only within their local professional and often geographical group. The 24 participants reported a total of 194 entities with which they shared climate information (inclusive of participants them- 
selves). Of these, none were international entities; 47 were federal, state or local government entities; 15 were non-governments organisations; 79 were community-based organisations and members; six were mass media (e.g., tv, radio or newspaper); seven were mass communication channels (e.g., internet or mobile); five were social media; and three were research centres. In addition, there were 32 other entities, such as individuals, friends and neighbours. Figure $2 b$ shows the climate information share network. The average degree of each node in this network was 1.990, with an average distance or reach for each node of 4.249. This network was far more fractious than the information access network (Figure $2 \mathrm{a}$ and Table 4), with seven components with a fragmentation factor of 0.449 . The main component had a diameter of 7 with a degree of closure of 0.007 (for full cohesion measures, please see Table 5). Further analysis of the share network using Keyplayer software revealed that the local radio station (\#6) along with two key individuals $(\# 26,54)$ could reach approximately $70 \%$ of the entire network (see Table 6). The key nodes with the longest reach were those who communicated information to government in addition to community-based organisations.

\subsubsection{Bega}

As well as accessing climate information from a diverse range of sources, participants also disseminated their knowledge broadly. The 29 participants reported a total of 209 entities with which they shared climate information (inclusive of participants themselves). Of these, 47 were federal, state or local government entities; 51 were NGOs; 77 were CBOs and members; nine were mass media (e.g., tv, radio or newspaper); one was a mass communication channel (e.g., internet or mobile); eight were social media; and one was a research centre (Table 4 ). In comparison to the network relating to the access of information, there were no international entities identified in the share network. In addition, there were 16 other entities in the share network, such as individuals, friends and neighbours. Figure $2 \mathrm{~d}$ shows the entire climate information disseminating network with Table 4 denoting network and node statistics. Analyses of the network measures show that the average degree of each node was 1.2, with an average distance of 1.4. This network was more fractious compared to the information access network, with 209 components with a fragmentation factor of 0.991 . The diameter, however, decreased from 4 to 3 , indicating there may be hubs working in the network (for full cohesions measures, please see Table 5).

The Keyplayer analysis demonstrated that three key nodes were effective in disseminating climate information to $79.5 \%$ of the network. These nodes included two individuals: \#I21—state government Local Land Services (LLS) and \#I28-CBO. The third key node was an aggregated informal node of "friends" \#P76 as reported by a number of participants (see Table 6).

\subsubsection{Orange}

In total, the 31 participants interviewed in this study shared climate change information with 205 nodes (including the participants themselves). Of these, there were no international entities, 84 government nodes, 28 non-government organisations (NGOs), 42 community-based organisations (CBOs), five mass media ( $t v$, radio or newspaper), three mass communication channels (e.g., internet or mobile), one social media (e.g., twitter), 18 research organisations and 24 others.

For this network, the average degree of each node was 1.1, with an average distance or reach for each node of 2.6. In common with the other regions, this network was more fractious compared to the information access network (Figure $2 f$ and Table 5), with 205 components with a fragmentation factor of 0.9 . The main component of the network had a diameter of 8 (meaning it would take 8 steps to make a path through this network) with a degree of closure of 0.1 (Table 5). Within this network, there are instances where interviewees shared with nodes that were not connected to other parts of the network, creating small, isolated components within the network. 
Keyplayer analysis demonstrated that three key nodes were the most effective in disseminating climate information: \#I28 - state government, \#I12-NGO and node \#I17-CBO. These three key nodes reached approximately $50 \%$ of the share network. See Table 6 .

\section{Discussion}

Within each of these case studies, there are similarities and differences among the networks which may have been shaped by a range of factors including the presence of a significant NRM-dependent industry (e.g., oysters, dairy and wine in Shoalhaven, Bega and Orange, respectively), geography (e.g., coastal, inland and estuaries) and the presence of individuals or organisations acting as boundary spanners. Within the business sector, knowledge networks may provide significant competitive advantage [36], whereas in adaptation to climate change, knowledge is a key component of adaptive capacity that not only enhances social resilience but, in cases of exposure to extreme weather, can save lives [37]. Within the primary industry sector, individuals with stronger knowledge networks (and weaker social ties) are more likely to undertake transformational adaptations within their businesses [38]. Despite the importance of knowledge flow, information and policy dissemination within government is often siloed [39,40], and it can be difficult to share information within fragmented communities [15]. Revealing the diversity of structures of knowledge networks allows for potential interventions [41] within communities, government and the private sector. While information was accessed from and shared with predominantly government actors in all three regions, the regional network statistics (Table 4) suggest that formal government networks for climate information interact with large informal networks; this may be due to their interaction with a range of media. In each region, informal access and share networks were larger than formal networks. The regions also differed in the types of actors in the network. For example, international sources of information appeared in the Shoalhaven access network, while Orange had a significantly higher presence of nodes representing research bodies in both the access and share networks. In both Shoalhaven and Bega, community-based organisations had a strong presence in the share networks.

The SNA in these regions demonstrated the influence of primary industries on the network, which may influence community action on adaptation to climate change. In two regions (Shoalhaven and Orange), a common feature of the share network structures was the presence of small networks or "cliques" around the periphery of the main network (Figure 2b,f). These cliques were commonly associated with a locally important agri-food industry. For example, in Shoalhaven, the key primary industry was oyster farming; in Bega, it was the dairy industry; and in Orange, the viticulture sector appeared significant. In Shoalhaven, the first commercial oyster lease was issued to George Hasier in 1882 [42]. Over 135 years later, the industry still survives in the Shoalhaven estuary, though at times with variously larger and smaller numbers of farmers [43]. The oyster industry in Shoalhaven remains a global enterprise [43]; however, the potential sensitivity of the industry to climate change impacts is well documented and is a likely driver of knowledge acquisition to support adaptive management responses [44]. For a business to succeed, the oysters must be healthy, and for oysters to be deemed healthy according to food safety standards, the water within the estuary must be tested to ensure that it fits within salinity and temperature parameters [45]. Water monitoring occurs in specific areas of the estuary depending on the location of "oyster leases". Although there is consideration of what is happening both upstream and downstream from the oyster farm, the product is dependent on conditions within the estuary. This focus of discerning and discrete sharing is reflected within the share network. In the Shoalhaven share network, there are clusters of informants around the perimeter of the image (Figure $2 b$ ). This may be indicative of the nature of estuaries and the need to monitor and manage the health and wellbeing of each specific estuary. As such, the information may become locked within estuary systems.

In Bega Valley, the "Bega Co-operative Creamery Company" was established in 1899, and has been operating within the region consistently for over 100 years (now called 
"Bega Cheese Limited") [46]. The sensitivity of dairy production to animal health under climate change [47] has ensured close ties between the dairy industry and government research, development and extension services to aid in the management of weather extremes (in particular, Local Land Services, an agency established specifically to act as a conduit between industry and government). The dairy industry in NSW, and in particular, Bega Cheese (being a cooperative), has been key to sharing information between farms and families for generations. This intergenerational connection has meant that individuals who once worked on dairy farms or were members of dairy farming families gravitated towards council or government positions, facilitating information transfer within both formal (through government) and informal (family and community-based organisations) channels. Rather than appearing as isolates or cliques, in Figure $2 d$, the dairy industry is embedded in the large network component in the top right quadrant of the image. In addition, the greater degree of isolation of the Bega Valley Region owing to its distance from a major urban centre may have contributed to a culture that supports greater local collaboration and communication.

In Orange, again there are industry dynamics at play. Here, a burgeoning wine industry operating for the past 20 years is represented within the share image in the top right-hand corner as a single large clique (Figure $2 \mathrm{f}$ ). Wine quality is particularly sensitive to changes in temperature [48], and the industry's knowledge needs are serviced by Wine Australia [49]. The industry appears to share knowledge about climate change internally, but not with the larger "community" component in the lower left-hand section. This industry is comparatively new to the region, and the Orange share network structure suggests that the climate change information was staying within this discrete community. In addition, the information shared by viticulturists may be specific to management practices within the industry (e.g., grape variety selection and specific irrigation for vines) and of limited value to the broader community.

The fact that natural resource-dependent industries are intimately connected to regional climate and rely on climate change information to ensure industry productivity and survival may have an impact on the operation of the networks. Further examination of knowledge diffusion requires use of network cohesion measures within UCInet (SNA-specific software). The specific measures useful to address network operation are: average degree-is the average number of connections each node has; fragmentation-how fractured the network is; average distance (the average reach of each node) and diameter (number of nodes to make a path through the network). Diameter is a network measure of the popularised concept of "Kevin Bacon's law", otherwise known as "small worlds". The concept posits that a maximum of six steps is required to span the network. In the instance of "Kevin Bacon's law", every Hollywood actor/actress is not greater than six degrees of separation (or six steps away) from Kevin Bacon. In our regional share networks, the prominence of different industry dynamics is evident (Figure 2b). In Shoalhaven, there were oyster farmers discussing information in their estuary; in Bega, the longstanding Bega Dairy Cooperative was very effective in communicating information to its members (active for approximately 100 years). However, in Orange, the wine industry was isolated, is reasonably new to the region (approximately 20 years) and funds research and develop that is both industry and region specific (Figure 2f). This qualitative explanation of network operation is supported through the network cohesion measures from Table 5. For example, the diameter of the Orange access network is 3 , meaning that information could be diffused in three steps within the main component. However, the diameter of the Orange share network was 8 , meaning the main network component was more fragmented due to the concentration of the information about adaptation in the isolated viticulture sector.

Boundary spanners are individuals able to operate at the boundary between science and policy, which involves mediating, bridging and brokering knowledge [50]. Boundary spanners existed in each of our regional networks, and these were identified through key player analysis. Boundary spanners are the key players at strategic points in the network (Table 6). Across access networks, these were generally nodes with a formal role in 
information dissemination and were often non-human sources (e.g., media and web sites). However, in the share networks, these strategic nodes had more informal roles and tended to be individuals. Examined through the lens of local industry narratives, specific attributes of the access and share key players support evidence that rural Australia considers some sources of information on climate change as more trustworthy (e.g., independent scientists) than others (e.g., politicians, government and the media) [51]. For example, CSIRO and the Bureau of Meteorology were among the most nominated information sources. Information sharing within agri-food industry sectors appears to have occurred frequently through trusted peer-to-peer networks which are known to support place-based adaptation and farmers' learning modes [52]. Where key players in networks were individuals, they often held multiple roles in the community, such as a formal role (e.g., in local government or government natural resource extension services such as LLS) or an informal role (e.g., coach of a sports team, involved in a CBO or gardening group). These individuals often had been in the region for a number of years, may have had familial ties spanning generations, generally had a family of their own and had an extensive personal social network, including a varied audience allowing for wide reach throughout the community. This study has provided empirical evidence of typologies of a regional knowledge broker that may assist in their identification in other settings.

In conclusion, each region in our study had an "industry" that was important in driving knowledge acquisition and, to a lesser extent, sharing knowledge about climate change in support of adaptation (oysters, dairy and wine). These industries are intimately linked to climate and drive the science which in turn helps form the empirical evidence for policy. This information may not be always closely linked to a broader community network (such as in Orange). In these instances, knowledge may be "locked up" and not diffuse outside the industry. However, in cases where the industry sector is deeply embedded in the community, such as the dairy industry in Bega, knowledge networks appear to have a more effective structure. There is an inherent danger of collapse of information exchange in relatively small regional networks that rely on a limited number of key nodes acting as hubs [53,54]. For example, government agencies experience significant turnover of staff through churn and restructure, and some of the key nodes identified in our networks have been lost to the region or have changed formal roles since the completion of our analysis. Further, there are opportunities for improved knowledge exchange when it comes to isolated cliques, as these networks may require specific and bespoke information channels and/or programs to be developed.

We believe our analysis of regional climate change information networks has barely "scratched the surface", and we recognize that there are some limitations to this work. Firstly, it is difficult to determine how much the extent of the networks revealed in our study might have been expanded through continued sampling of nodes. However, the opportunity for further snowballing was limited due to the scale and scope of the project. Clearly, we did not reach every aspect of regional society, and in some instances, although community members were contacted (e.g., within the regional chambers of commerce), they were unable to participate in the study due to the timing and availability. Secondly, our snowball sampling connected mainly to natural resource/environment actors. While these actors are of significance as seekers and users of climate information, other community perspectives (e.g., arts and cultural community) are equally important and may have yielded additional insights.

Despite these limitations, this study of the structure of regional information exchange through social network analysis allowed the invisible connections among a section of three regional communities to be revealed and facilitated greater understanding of the operation of knowledge systems. Involving policy makers in a co-designed approach to the research and maintaining strong communications between the research team and the information users, New South Wales Office of Environment and Heritage (an agency of the NSW Government), ensured that the gaps and insights identified through the case studies were directly shared with policy audiences. Policy changes at a varying 
pace, sometimes slowly, sometimes rapidly-just like climate impacts and adaptation. Understanding how knowledge is dispersed through communities may assist in more efficient and effective climate policy information and, therefore, help reduce the impacts and improve the management of climate change for regional communities.

Author Contributions: Conceptualization, R.C. and B.J.; Data curation, R.C.; Formal analysis, R.C. and B.J.; Funding acquisition, B.J.; Investigation, R.C.; Methodology, R.C. and B.J.; Project administration, B.J. and T.G.M.; Software, R.C.; Supervision, B.J.; Visualization, R.C.; Writing—original draft, R.C., B.J. and T.G.M.; Writing-review \& editing, R.C. and B.J. All authors have read and agreed to the published version of the manuscript.

Funding: This research was funded by the New South Wales Office of Environment and Heritage through the Adaptive Communities Node 2013-2019.

Institutional Review Board Statement: The study was conducted according to the guidelines of the Declaration of Helsinki, and approved by the University of Technology Ethics committee (approval number 13015 approved 11 July 2013) and by the CSIRO Social Science Human Research Ethics Committee (approval number 077/13 approved 4 September 2013).

Informed Consent Statement: All participants provided informed consent as per the approved ethics.

Data Availability Statement: Due to confidentiality conditions required for ethics approval, the raw data are not publicly available.

Acknowledgments: Thank you to Chris Cvitanovic, Ben Harman and Anne-Maree Dowd for their contribution to the original project. Thanks also to the internal reviewers, Terry Royce, Pam Ryan and Roel Plant.

Conflicts of Interest: The authors declare no conflict of interest.

\section{References}

1. Pidgeon, N.; Demski, C.; Butler, C.; Parkhill, K.; Spence, A. Creating a national citizen engagement process for energy policy. Proc. Natl. Acad. Sci. USA 2014, 111 (Suppl. 4), 13606-13613. [CrossRef]

2. Serrao-Neumann, S.; Schuch, G.; Harman, B.; Crick, F.; Sano, M.; Sahin, O.; van Stadin, R.; Baum, S.; Low Choy, D. One human settlement: A transdisciplinary approach to climate change adaptation research. Futures 2015, 65, 97-109. [CrossRef]

3. Di Gregorio, M.; Fatorelli, L.; Paavola, J.; Locatelli, B.; Pramova, E.; Nurrochmat, D.R.; May, P.H.; Brockhaus, M.; Sari, I.M.; Kusumadewi, S.D. Multi-level governance and power in climate change policy networks. Glob. Environ. Chang. 2019, 54, 64-77. [CrossRef]

4. Mastrandrea, M.D.; Heller, N.E.; Root, T.L.; Schneider, S.H. Bridging the gap: Linking climate-impacts research with adaptation planning and management. Clim. Chang. 2010, 100, 87-101. [CrossRef]

5. Dodman, D.; Mitlin, D. Challenges for Community-based Adaptation: Discovering the potential for transformation. J. Int. Dev. 2013, 25, 640-659. [CrossRef]

6. Smit, B.; Pilifosova, O. From Adaptation to Adaptive Capacity and Vulnerability Reduction. In Climate Change, Adaptive Capacity and Development; World Scientific: Singapore, 2003; pp. 9-28. [CrossRef]

7. Green, D.; King, U.; Morrison, J. Disproportionate burdens: The multidimensional impacts of climate change on the health of Indigenous Australians. Med. J. Aust. 2009, 190, 4-5. [CrossRef] [PubMed]

8. Adger, W.N. Social Capital, Collective Action, and Adaptation to Climate Change. Econ. Geogr. 2003, 79, 387-404. [CrossRef]

9. Dunford, S. Attributes of good governance for effective adaptation action and regional transitions. In Proceedings of the 4th Practical Responses to Climate Change Conference, Melbourne, Australia, 8-10 May 2018; p. 63.

10. Blair, D. All the Ships that Never Sailed: A General Model of Illicit Market Suppression; Georgetown University, Georgetown UniversityGraduate School of Arts \& Sciences: Washington, DC, USA, 2014.

11. Cunningham, R.; Cvitanovic, C.; Measham, T.; Jacobs, B.; Dowd, A.-M.; Harmq, B. Engaging communities in climate adaptation: The potential of social networks. Clim. Policy 2016, 16, 894-906.

12. Hens, R.; Wilk, B.; Persson, Å.; Uittenbroek, C.; Wamsler, C. Mainstreaming climate adaptation: Taking stock about "what works" from empirical research worldwide. Reg. Environ. Chang. 2018, 18, 1201-1210. [CrossRef]

13. Muccione, V.; Huggel, C.; Bresch, D.N.; Jurt, C.; Walliamann-Helmer, I.; Mehra, M.K.; Caicedo, J.D.P. Joint knolwedge production in climate change adapatation networks. Curr. Opin. Envrion. Sustain. 2019, 39, 147-152. [CrossRef]

14. Pelling, M. Adaptation to Climate Change: From Resilience to Transformation; Routledge: London, UK, 2010.

15. Borgatti, S.P.; Everett, M.G.; Johnson, J.C. Analyzing Social Networks; Sage Publications: London, UK, 2013.

16. Bodin, O.; Prell, C. Social Networks and Natural Resource Management: Uncovering the Social Fabric of Environmental Governance; Cambridge University Press: Cambridge, UK, 2011. 
17. Schmid, J.C.; Knierim, A.; Knuth, U. Policy-induced innovations networks on climate change adaptation-An ex-post analysis of collaboration success and its influencing factors. Environ. Sci. Policy 2016, 56, 67-79. [CrossRef]

18. Lotz-Sisitka, H.; Ali, M.B.; Mphepo, G.; Chaves, M.; Macintyre, T.; Pesanayi, T.; Wals, A.; Mukute, M.; Kronlid, D.; Tran, D.T.; et al. Co-designing research on transgressive learning in times of climate change. Curr. Opin. Environ. Sustain. 2016, 20, 50-55. [CrossRef]

19. State of New South Wales. Adapt NSW: Climate Projections for Your Region. Available online: https://climatechange. environment.nsw.gov.au/Climate-projections-for-NSW/Climate-projections-for-your-region (accessed on 20 May 2020).

20. Shoalhaven City Council. Available online: https://www.shoalhaven.com/visitor-information (accessed on 10 October 2018).

21. Bega Valley Shire Council. About the Bega Valley Shire. Available online: https://www.begavalley.nsw.gov.au/cp_themes/ default/page.asp?p=DOC-KWS-62-56-27 (accessed on 10 March 2020).

22. Bega Valey Shire Council. History of the Shire. Available online: https://www.begavalley.nsw.gov.au/cp_themes/default/page. asp? $\mathrm{p}=$ DOC-KWS-62-56-27 (accessed on 10 March 2020).

23. Harman, B.; Rylance, K.; Brown, P.; Cunningham, R.; Jacobs, B.; Measham, T. Engaging Local Communities in Climate Adaptation: A Social Network Perspective from Orange Valley, New South Wales, Australia; CSIRO: Canberra, Australia, 2016.

24. Orange Regional Museum. A Short History of Orange. Available online: http://www.orange.nsw.gov.au/wp-content/uploads/ 2018/08/Short-History-of-Orange.pdf (accessed on 17 February 2020).

25. Visit NSW. Visit NSW-Welcome to Orange. Available online: https:/ / www.visitnsw.com/destinations/country-nsw / orange-area (accessed on 20 December 2020).

26. Newcrest Mines Limited. Our Assets-Cadia. Available online: https://www.newcrest.com/our-assets/cadia (accessed on 20 December 2020).

27. NSW Government, Office of Environment and Heritage. Central West and Orana Climate Change Snapshot; Office of Environment and Heritage: Sydney, Australia, 2014; p. 16.

28. NSW Government, Office of Environment and Heritage. South East and Tableands Climate Change Snapshot; Office of Environment and Heritage: Sydney, Australia, 2014; p. 16.

29. NSW Government, Office of Environment and Heritage. Illawarra Climate Change Snapshot; Office of Environment and Heritage: Sydney, Australia, 2014; p. 16.

30. Prell, C. Social Network Analysis: History, Theory \& Methodology; SAGE Publications Ltd.: London, UK, 2012.

31. Cunningham, R.; Cvitanovic, C.; Measham, T.; Jacobs, B.; Dowd, A.; Harman, B. A preliminary Assessment into the Utility of Social Networks for Engaging Local Communities in Climate Adaptation Policy: Working Paper Prepared for NSW Office of Environment $\mathcal{E}$ Heritage; Institute for Sustainable Futures: Sydney, Australia, 2014.

32. Cunningham, R.; Jacobs, B.; Measham, T.; Harman, B.; Cvitanovic, C. Social Network Analysis: A Primer on Engaging Communities on Climate Adaptation in New South Wales, Australia; University of Technology Sydney: Sydney, Australia, 2017.

33. Harman, B.; Cunningham, R.; Cvitanovic, C.; Jacobs, B.; Measham, T. Community Based Perspectives on Climate Change and Adaptation in the Shoalhaven Region; CSIRO: New South Wales, Australia, 2015.

34. Harman, B.; Cunningham, R.; Jacobs, B.; Measham, T.; Cvitanovic, C. Engaging Local Communities in Climate Adaptation: A Social Netework Perspective from Bega Valley, New South Wales; CSIRO: Canberra, Australia, 2015.

35. Borgatti, S.P. Identifying sets of key players in a social network. Comput. Math Organ. Theory 2006, 12, 21-34. [CrossRef]

36. Phelps, C.; Heidl, R.; Wadhwa, A. Knowledge, Networks, and Knowledge Networks: A Review and Research Agenda. J. Manag. 2012, 38, 1115-1166. [CrossRef]

37. Sharpe, S.; Delaney, C.; Cunningham, R. Forced Innovation: Business Preparedness and Recovery after Extreme Weather Events; University of Technology Sydney: Sydney, Australia, 2019.

38. Dowd, A.; Marshall, N.A.; Fleming, A.; Jakku, E.; Gauillard, E.; Howden, M. The role of networks in trans- forming Australian agriculture. Nat. Clim. Chang. 2014, 4, 558-563. [CrossRef]

39. Gogglin, C.L.; Cunningham, R.; Summerell, G.; Leys, J.; Barrett, T.; Auld, T.D.; Oliver, I.; Littleboy, M. Exploring the networks of government scientists using Social Network Analysis: A scoping study. In Proceedings of the 21st International Congress on Modelling and Simulation, Gold Coast, Australia, 29 November-4 December 2015.

40. Cunningham, R.; Gogglin, C.L. Changes in Social Connection in a Government Research Network; University of Technology Sydney \& NSW Government: Sydney, Australia, 2019.

41. Cvitanovic, C.; Cunningham, R.; Dowd, A.-M.; Howden, S.M.; Putten, E.I.V. Using Social Network Analysis to Monitor and Assess the Effectiveness of Knowledge Brokers at Connecting Scientists and Decision-Makers: An Australian case study. Environ. Policy Gov. 2017, 27, 256-269. [CrossRef]

42. Pickard, N. Father of Shoalhaven's oyster industry left strong legacy. In South Coast Register; South Coast Register: Nowra, New South Wales, Australia, 2018. Available online: https://www.southcoastregister.com.au/story/5170578/father-ofshoalhavens-oyster-industry-left-strong-legacy/ (accessed on 11 November 2020).

43. Huntsdale, J. The Oyster is Jilm Wild's World as He Celebrates a Life Growing Seafood on the Shoalhaven Rivers; ABC Illawarra: Illawarra, New South Wales, Australia, 2017.

44. Leith, P.B.; Haward, M. Climate Change Adaptation in the Australian Edible Oyster Industry: An Analysis of Policy and Practice; University of Tasmania: Hobart, Tasmania, 2010.

45. Food Agility CRC. Food Safety in the NSW Oyster Industry; Food Agility CRC: Sydney, Australia, 2018. 
46. Cheese, B. ACCC Inquiry into the Australian Dairy Industry; Bega Cheese: Bega Town, Australia, 2016.

47. Harrison, M.T.; Cullen, B.R.; Rawnsley, R.P. Modelling the sensitivity of agricultural systems to climate change and extreme climatic events. Agric. Syst. 2016, 148, 135-148. [CrossRef]

48. Webb, L.B.; Whetton, P.H.; Barlow, E.W.R. Climate change and winegrape quality in Australia. Clim. Res. 2008, 36, 99-111. [CrossRef]

49. Australian Government, Wine Australia. Available online: https://www.wineaustralia.com/ (accessed on 15 December 2020).

50. Goodrich, K.A.; Sjostrom, K.D.; Vaughan, C.; Nichols, L.; Bednarek, A.; Lemos, M.C. Who are boundary spanners and how can we support them in making knowledge more actionable in sustainability fields? Curr. Opin. Environ. Sustain. 2020, 42, 45-51. [CrossRef]

51. Buys, L.; Aird, R.; van Megen, K.; Miller, E.; Sommerfeld, J. Perceptions of climate change and trust in information providers in rural Australia. Public Underst. Sci. 2014, 23, 170-188. [CrossRef]

52. Šūmane, S.; Kunda, I.; Knickel, K.; Strauss, A.; Tisenkopfs, T.; Rios, I.D.I.; Rivera, M.; Chebach, T.; Ashkenazy, A. Local and farmers' knowledge matters! How integrating informal and formal knowledge enhances sustainable and resilient agriculture. J. Rural Stud. 2018, 59, 232-241. [CrossRef]

53. Doyle, J.C.; Alderson, D.L.; Li, L.; Low, S.; Roughan, M.; Shalunov, S.; Tanaka, R.; Willinger, W. The "robust yet fragile" nature of the Internet. Proc. Natl. Acad. Sci. USA 2005, 102, 14497. [CrossRef] [PubMed]

54. Piccolo, S.A.; Lehmann, S.; Maier, A. Design process robustness: A bipartite network analysis reveals the central importance of people. Des. Sci. 2018, 4. [CrossRef] 